\title{
All in a day's work
}

\section{Working-class heroes as videogame protagonists}

\author{
Michael Iantorno, Courtney Blamey, Lyne Dwyer, \\ \& Mia Consalvo
}

Department of Communication Studies, Concordia University, Canada

\begin{abstract}
Class depictions in videogames are prevalent, yet understudied. In this article, we analyse how the working class - particularly working-class men - have been depicted in videogames over the past 30 years. In doing so, we bring together a class- and gender-based analysis to study how narratives, representations, gameplay, and game systems construct the "workingclass hero" as a central protagonist. This is done by examining eight paired examples of videogames that feature working-class characters in central roles, including janitor, firefighter, taxi driver, and bartender. Our analysis finds that some roles are glorified (such as firefighters), positioning their protagonists in direct conflict with white-collar settings and antagonists. However, many other roles task players with "doing their job" in the face of repetitive (and sometimes outlandish) working conditions. Through these examples, we document the portrayal of working-class videogame heroes, noting how videogames can both reinforce and subvert common media tropes.
\end{abstract}

Keywords: videogames, working class, blue collar, narratives, gameplay

\section{Introduction}

When considering media, particularly in the Western context, one of the most understudied axes of identity is class. As Richard Butsch (2017:38) laments in his analysis of class and gender in American television sitcoms, "Hollywood, as with most Americans, has a vocabulary and conceptual deficit when it comes to class". This lack may be, in part, because class has historically been difficult to define. The use of strictly economic lenses - such as Marxist theoretical frameworks - is one starting point, but such approaches fail to capture key elements of lived class experience and its cultural expressions. Joan C. Williams emphasises that class is not solely about money, but often manifests as a "cultural tradition that people riff off as they shape their everyday behaviour and make sense of their lives" (2017: 12). Although a comprehensive definition is likely impossible, we loosely characterise class as being constituted from "a combination of economic (income, wealth) and social factors (family background, education, occupation, social prestige)" with a particular concern for how it is "expressed in lifestyle, values, behav-

Iantorno, M., Blamey, C., Dwyer, L., \& Consalvo, M. (2021). All in a day's work: Working-class heroes as videogame protagonists. Nordicom Review, 42(S3), 88-110. https://doi.org/10.2478/ nor-2021-0028 
ior, manners" (Deery \& Press, 2017: 6). Class is also inherently relational, with class distinctions derived from differences and conflict. Thus, a great deal of scholarly work attempts to identify social and cultural markers that signify class - ones that reproduce class differences and make them seem natural or inevitable.

These so-called everyday experiences of class are depicted in popular fictional media in numerous and often contradictory ways. While "middle classness" is often unmarked and rendered invisible, representations of the working class, or blue-collar workers, have received some scholarly attention. Butsch's (2017) longitudinal study of American television programmes, for example, reveals that upper-middle-class sitcoms far over-represent their demographic, while working-class families are relatively scarce. One troubling theme that has emerged from these programmes is the prevalence of the "fool" trope, most commonly depicted as a working-class male breadwinner who is "a buffoon or bungler, often well-meaning and warm-hearted, but incompetent, immature, ignorant, irresponsible" (Butsch, 2017: 41). Augie Fleras and Michael Shane Dixon (2011) further elaborate that, although blue-collar patriarchs have become a target of our ridicule, such depictions could be viewed as distortions of positive workingclass ideals such as honesty, reliability, and a strong work ethic - traits that have been "reframed as working-class stupidity - a weakness to make fun of, especially by comparison to their upper-class superiors" (Fleras \& Dixon, 2011: 583). Reflecting on how the American sitcom has historically demeaned and demasculinised the working class, Fleras and Dixon document a sharp diversion of this trope in reality-TV shows like The Deadliest Catch and Ice Road Truckers, which chronicle workers in physically dangerous or demanding occupations in an attempt to re-masculinise them. Notably, the authors extract several values from these shows that contribute to the modern imaginary of working-class occupations: underappreciation, resiliency in the face of danger, perseverance, autonomy, hard work, and camaraderie (Fleras \& Dixon, 2011). Overall, then, with depictions ranging from hapless bungler to rugged labourer, the working class is difficult to pin down.

Class depictions in videogames are also widespread but understudied, with this lack carrying over into the understanding of both the content of digital games as well as their reception. One of the earliest projects centred on class in videogames studied it alongside themes of gender and race, focusing on Nintendo home-console titles in the early 1990s and scrutinising how these games were "apt to replicate in their structure the values and activities associated with the dominant ideology" (Gailey, 1993: 81). Gailey argues that videogames reinforce class stereotypes - such as the persistent, violent depiction of the urban jungle - as well as predetermined hierarchies based on wealth and power - but her study only scratches the surface of a much larger topic. More recent research on game content has largely focused on gender, sexuality, and race and ethnicity, with class either ignored or relegated to a secondary axis, such as "race and class". For example, one widely cited study conducted a virtual census of characters in top-selling videogames and focused on gender, race and ethnicity, and age, but did not attempt to examine class (Williams et al., 2009). Other work has given us valuable insights into how sexuality and gender are present in games (Chess, 2017; Shaw, 2014), but as of yet, little significant work has socioeconomic class as the primary focus of analysis for studying game content. The growing trend of dystopian backdrops in popular videogames has sparked some insightful research, particularly in regard to how recessionary (Pérez-Latorre et 
al., 2017) and dystopian (Pérez-Latorre \& Oliva, 2019) themes inflict neoliberal values into titles, but the narrative and ludic aspects of socioeconomic class in videogames still begs for additional analysis.

To help remedy this shortcoming in game studies literature focusing on socioeconomic class, ${ }^{1}$ we present in this article a series of case studies on how the working class have been depicted in videogames over the past four decades. In doing so, we bring together a class- and gender-based analysis to study how narratives, representations, gameplay, and game systems construct the "working-class hero" (or failed hero) as a central protagonist. We have opted to cast a wide net when considering what occupations constitute the working class - ranging from working-poor frontline workers to stereotypically blue-collar labour positions - to provide variety in case studies and allow for points of comparison. Our analysis uses eight paired examples of videogames featuring working-class characters in starring roles, focusing on the occupations of taxi driver, janitor, bartender, and firefighter. These occupations were chosen for a multitude of reasons: their prevalence in popular media, which allowed us to build upon existing research on socioeconomic class; the availability of titles in which working-class characters are playable and easily identifiable; and, finally, the portrayal of these occupations over time, which allowed us to contrast content in both early and modern videogames. However, we must also acknowledge the dearth of titles featuring these sorts of occupations in starring roles. One of the beneficial side effects of this limited selection is that our games hail from a variety of genres and - as we will describe more fully later on - both embrace and subvert the conventions and traditions of such genres.

Games offer us insights into how we understand working-class jobs that go beyond traditional media representations, not just because of their additional narratives and representations, but through their procedural systems and their ability to render occupational simulations of varying complexity. Individuals enact class roles through play, embodying working-class experiences and making decisions within specific labour contexts. As we argue further within the following sections, power relations due to class positions are a central element in many of these games, demonstrating how simulated jobs retain - and often highlight - the ideological positionings of their origins in everyday life. Therefore, this article scrutinises tangible simulations of blue-collar labour, rather than aesthetic appropriations, such as Mario's questionable résumé as a plumber. Gonzalo Frasca (2003: 225) emphasises that simulations "express messages in ways that narrative simply cannot" and are commonly leveraged as a way to understand complex systems. Simulations often model systems by reducing their complexity to a concise subset of behaviours or rules, such as how a flight simulator "allows the player to perform actions that will modify the behavior of the system in a way that is similar to the behavior of the actual plane" (Frasca 2003: 224). As players engage with simulators, they discover the rules for operating them and, in the case of most videogames, how to succeed at them. Constructing these simulations cannot be framed as a value-neutral exercise, as the ability to include or exclude rules and determine a winning condition for a livelihood is, of course, deeply ideological. Accordingly, analysing games that simulate jobs allows us to determine at least some of the ways that occupations are constructed and contemplated in contemporary culture: Which jobs are deemed desirable and which are not? What control do we have within our jobs in terms of structuring our time? What does it mean to be successful at a job? How can one fail? 
We analyse eight games in this article: Crazy Taxi (1999) and Neo Cab (2019), which focus on the rapidly changing profession of driver-for-hire; Tapper $(1983)^{2}$ and VA11 HALL-A: Cyberpunk Action Bartender (2016), where bartending takes centre-stage; the Space Quest series (1986-1995) and Diaries of a Spaceport Janitor (2016), rooted in fantastical depictions of janitorial work; and The Firemen (1994) and Real Heroes: Firefighter (2009), which explore the blue-collar heroics of fire service workers. Our analysis of these titles relies on the creation of a gameplay log, a dynamic method in which a researcher studies and documents "emergent behaviour or situations, the larger game world or system, and intertextuality as it is constituted with the game" (Consalvo \& Dutton, 2006). We played each game several times, taking notes and screenshots to document how each profession was presented, how mechanics within each game defined the scope and dynamics of each job, and how characters and narratives, as well as win-loss conditions, all constructed a sense of how each profession "should" be performed. Each of the following sections explores themes including the skills demanded from seemingly "unskilled" jobs, the failure of the working-class hero, and what changes games make to elevate seemingly mundane occupations to heroic status. Each game could be the topic of an entire paper on its own, or each paired set the subject of much greater attention. Our goal here is not an exhaustive analysis, but rather to demonstrate the rich potential of studying socioeconomic class as it exists in current and past videogames, and the wide variety of ways it is represented in even a handful of titles.

Our game selection was also influenced by a number of logistical factors. Due to our own language proficiencies, we were limited to games that featured an official English release - thus leaving out many Japanese-language games that may have proven relevant. Pragmatically, we also needed to play our selected titles in their entirety (without relying too heavily on secondary sources), which limited us to games accessible either via sources such as the Internet Archive or playable on legacy systems (such as PlayStation 2 ) and current systems to which we had access. In an effort to investigate how depictions of labour have changed over time, we made a concerted effort to seek out games released prior to 2000 as well as more contemporary titles. After compiling a list of potential candidates, we identified the presence of various occupational roles and noted where they repeated across varying games. We chose the four occupations discussed here due to their working-class nature, their presence in both earlier and later games, their diversity in genre and theming, and because they offered us games that appeared contextually rich. We do not suggest they are representative of all games that feature those occupations, but instead argue that even this limited selection features games with important arguments about class built into them.

\section{Who's gonna drive you home? Changing skillsets and driving for hire}

Games such as Crazy Taxi and Neo Cab allow the player to inhabit the role of a driver-for-hire, either as a taxi driver or for a rideshare service. They demonstrate (at least in a limited way) that real skills are demanded for these seemingly "unskilled" occupations and also that these skillsets change over time. The driver, as depicted in these games, has also evolved to be even more precarious and dependent on passenger goodwill. Both games highlight key elements of this working-class occupation: poor and variable compensation, high-stress conditions that place premiums on time and 
precision, and increasingly managing one's own and one's passengers' emotions or affective states.

In North America, driving a taxi cab is considered a job for unskilled workers. As of 2019, the median salary is USD 31,340 per year (U.S. News \& World Report, n.d.). For rideshare drivers, figures vary from USD 14,284 to more than USD 60,000, but it is at best precarious (Helling, 2020; Salaries HUB, n.d.). Beyond economics, driving for hire is often considered menial and low-status labour, with some employees likening it to "pulling rickshaws in India" (Mitra, 2008: 312). Sharma (2014: 56) argues that workers are viewed as "the expendable bodies of a labour force that can easily be replenished". Yet drivers labour in multiple ways to produce satisfied passengers. This includes not simply driving passengers to their destinations safely and on time, but also in managing the emotions and moods of passengers for tips or driver ratings. Drivers must also manage the "slow time" of waiting for or seeking fares and the "speeded-up time" of engaging with fares in conjunction with their own bodily and emotional needs and desires.

\section{Crazy Taxi}

Crazy Taxi is a 1999 open-world driving game developed by Hitmaker Studios and published by Sega for arcades and then for multiple game consoles. The game enacts picking up customers and delivering them to their destinations as quickly as possible. Players are rewarded with bonuses for engaging in jumps and other automotive tricks and are punished if they go over time by having passengers leave without paying. Passengers loudly voice both their approval and disapproval, complimenting flashy moves and quick service, as well as berating the player-as-driver for collisions, getting lost, and being slow to reach their destination. An in-game arrow points to one's destination, but the player can also take shortcuts across parks and sidewalks, and so forth. Crazy Taxi capitalizes on its 3D, open-world design by encouraging players to drive fast and perform flashy moves, pushing the player to drive quickly with its upbeat soundtrack.

Crazy Taxi players keep passengers happy through offering them the freedom to perform speed and skill - the pleasure of accelerating, jumping off ramps, making pedestrians scatter, or knocking down street signs - all will delight passengers, as long as they reach destinations on time. It reduces the job to a few components: there is no real downtime waiting for fares, vehicles never take damage or need to be serviced, and the player's avatar never needs to stop for rest or food. Driving is the core mechanic, and navigating the map brings success. Players are only berated by passengers if they lack knowledge of where to go or drive too slowly. Drivers do not worry about fulfilling the emotional needs of their passengers and are not able to engage in conversation with them - yet passenger commentary is a core feedback loop of the game. There is no guessing how one is doing. Drivers also never need to refill fuel, eat, or engage in maintenance routines. The "cab lag" discussed by Sharma that today's drivers endure is entirely absent from Crazy Taxi. The game instead focuses on speed and urgency as central experiences.

\section{Neo Cab}

Neo Cab was developed in 2019 by Chance Agency and published by Fellow Traveller. The player is Lina, one of the "last human drivers-for-hire". The plot involves trying to 
find your missing friend Savy (and solve the mystery surrounding her disappearance) while continuing to pick up passengers and "balance your own wellbeing with the needs of your pax as you strive to keep your perfect rating, and your job” (Neo Cab, n.d.).

In contrast to Crazy Taxi, the act of physically driving is gone, and the environment is a $2 \mathrm{D}$ comic-noir-style adventure game. Rather than navigating to a destination, the player must instead explore the choices of which passengers to pick up and how to respond to their conversational prompts. The stakes still revolve around customer satisfaction and associated earnings, however. Satisfying passengers requires reading the situation and determining whether to keep cool and stay aloof, or dive into a conversation and take a strong position - customer feedback is rarely as obvious as it is in Crazy Taxi. Instead, doing emotional labour becomes the way to keep one's job (Morton, 2018). Passengers have varying attitudes towards Lina, some seeing her as a fellow worker, and others as a relic of a dangerous practice - human-directed rather than autonomous cars. Here, the game takes up current politics around rideshare services, but fast-forwarding ahead from the taxi-Uber debate to the coming issue of driverless cars. In the game, a new bill is under consideration which would outlaw human-driven cars, named in response to a car crash that killed a dancer. It is also revealed through gameplay that the largest autonomous car company - Capra - is the one pushing the legislation the hardest. Lina is asked by various passengers about her opinion on the bill and the idea, leaving the player in the uncomfortable position of potentially advocating for the erasure of their job.

In $\mathrm{Neo} \mathrm{Cab}$, the role of driver-for-hire is still to ferry about passengers from one point to another, but the skills required shift from driving to talking. Neo $\mathrm{Cab}$ is also about managing emotions and recognising the leash that service jobs place on self-expression. This happens through the game's "Feelgrid" bracelet that Savy places on Lina's wrist at the start of the game. The bracelet operates as a mood ring, displaying different colours that mirror Lina's emotional state. For example, if Lina starts to anger, the colour red grows in intensity. Along with that change, Lina's potential conversational responses shift. As Lina grows angrier, all the potential responses a player can choose from deal with anger, and she is unable to choose a different emotionally based response. While ostensibly a commentary on how one's emotions lead one to different conversational outcomes, the system also operates as a commentary on the state of precarious, servicebased labour and how it can chill free expression. If you, as Lina, get too angry, you risk offending a passenger, and possibly losing your tip or receiving a lower rating. In this occupation, the game seems to say, the customer's mood must take precedence over your own.

While in Crazy Taxi the player can take the route they prefer - and take as long as they want (albeit while being insulted by passengers) - the worst that can happen is the passenger leaves without paying, possibly to potential game loss. Yet in Neo $\mathrm{Cab}$, where choices are ostensibly based on keeping passengers happy versus being true to oneself, even that ability is stripped away at times, as the player is forced to acquiesce, as the technology "reads their mood" and the system limits their choices. Some passengers treat you as less than human, with one insisting you are a robot. Driving in Neo Cab continues to provide above-average stress, but limits the flexibility not only of location and time with respect to work, but even how to respond to one's passengers and friends. 
Figure 1 Driving cabs and pleasing passengers

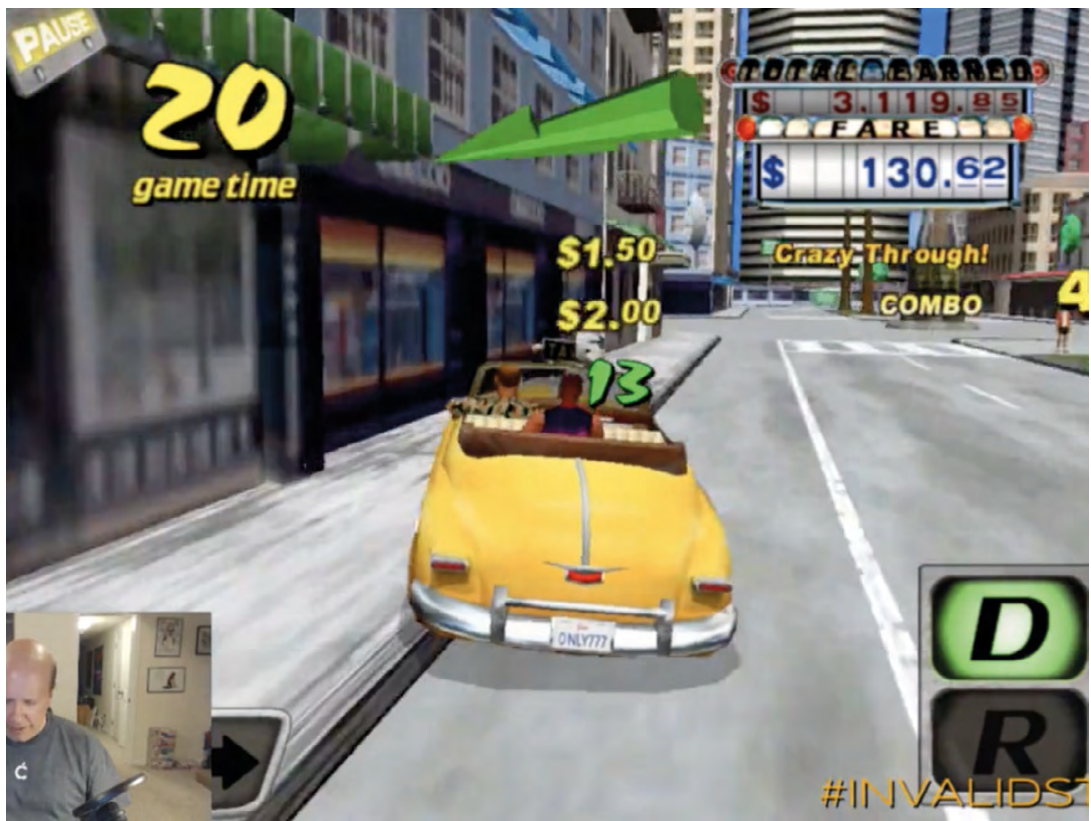

Comments: Crazy Taxi depends on pleasing passengers with speed and accuracy. Above, a player earns additional cash for aggressively skidding across a city sidewalk while a green countdown indicates how long they have to reach their next destination.

Source: Crazy Taxi (Hitmaker Studios, 1999)

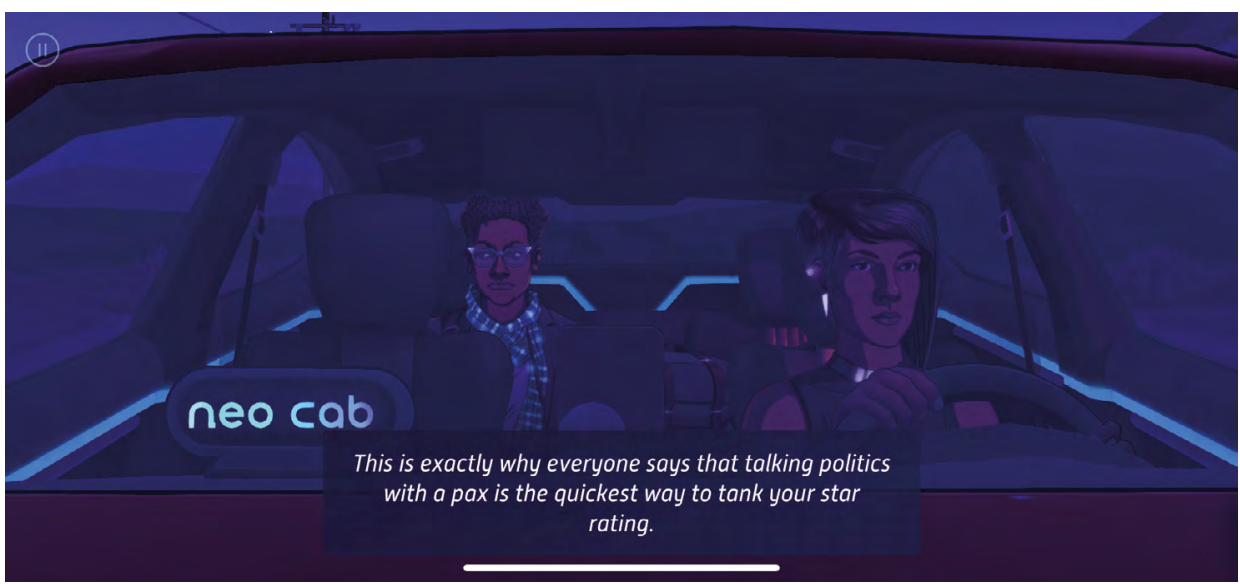

Comments: In Neo Cab, skills revolve around knowing what to say and managing passenger emotions. As seen above, bringing politics up during conversations can run the risk of a bad review.

Source: Neo Cab (Chance Agency, 2019)

Overall, both games do acknowledge the skills involved in seemingly unskilled labour. Crazy Taxi offers the player clear directions for what to do, and a pleasurable experience for developing and displaying requisite skills correctly. While taxi drivers of the 1990s could not crash through towns, they were made promises of eventual financial security (Aliyu, 2020). Neo Cab illustrates how starkly rideshare services have changed the 
driver-for-hire position, focusing on passenger mood management and self-regulation. Even if the player "plays by those rules" - if they can even figure out how to do so correctly - they still lose at the end. Neo Cab shows the job of driver-for-hire disappearing completely, due to eventual, and inevitable, automation.

\section{"On the rocks": The gendered working-class hero}

Tapper (Marvin Glass and Associates, 1983) and VA11 HALL-A: Cyberpunk Action Bartender ( $V: C A B)$ (Sukeban Games, 2016) both invoke the figure of the "failed" working-class hero, revealing the issue of precarity and emotional labour imbued and expected from positions in the service industry. Struggling to hold down one job is not characteristic of the working-class heroes typically encountered in videogames. Instead, these protagonists often strive to maintain their own lives while being required to expend emotional energy on others, all under the pressure of increasingly precarious labour conditions. They are not seen chasing after adventure or aiding a hero's journey. Instead, they represent the low-wage, everyday worker completing their daily routine of work and rest.

Bars and working as a bartender have been a historically tumultuous and gendered space. Despite now making up the majority of working bartenders in the US, for the longest time, women were not allowed to frequent bars and public houses, and subsequently had to fight for the right to be permitted to work in them (Lupton, 1979). The setting of the saloon is used in Tapper to signify a typically working-class masculine-dominated leisure space as the initial game environment. As the player proceeds through the levels, intermittent celebrations are indicated by sexualised female avatars dancing across the screen - reinforcing sexist gender roles and male fantasy within the leisure space of the saloon. However, the service industry has become increasingly feminised, "characterised by low wages and part time employment" (Sherman, 2009: 33). This feminisation of labour is present in "Valhalla", the bar in $V: C A B$, as it also exists as a leisure space in the form of a cyberpunk dive bar, but it is populated mostly by working-class women: interns, bionic sex workers, and police officers.

\section{Figure 2 Virtual bartending}

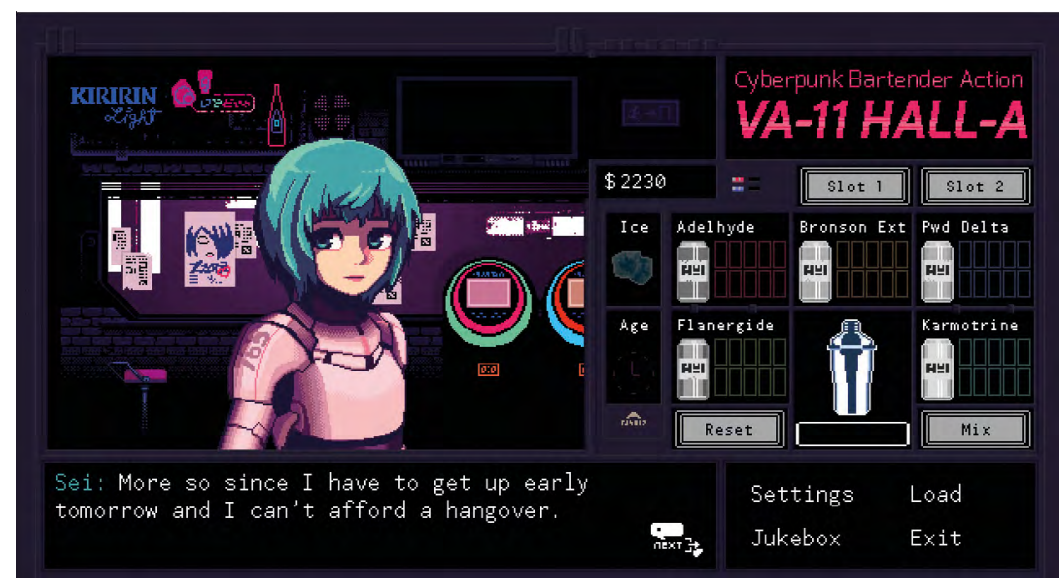

Comments: A police officer regularly visits the bar in V:CAB.

Source: VA11 HALL-A (Sukeban Games, 2016) 


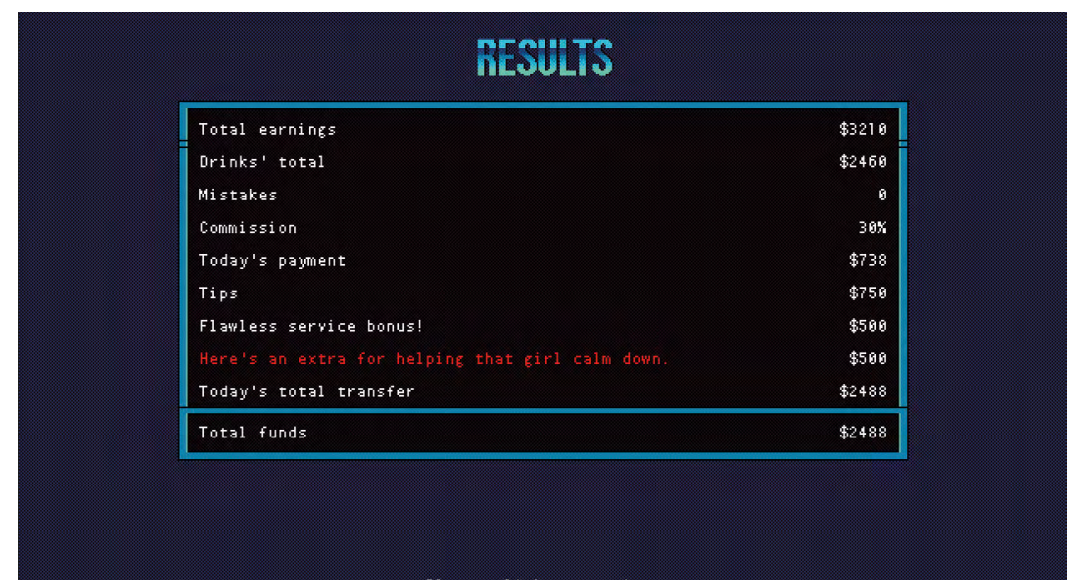

Comments: A typical end of day tally for Jill the bartender, including bonuses for having no mistakes and helping a customer calm down. Source: VA11 HALL-A (Sukeban Games, 2016)

\section{Tapper}

Tapper is a 1980s arcade cabinet game, franchised over the years by Root Beer, Budweiser, and Mountain Dew. The player manoeuvres a moustachioed male bartender between four kegs and down the bars in order to deliver drinks, collect glasses, and rush for tips before they disappear. Tapper has a low threshold for failure - if the player either misses serving a drink or catching an empty glass, the game is over.

Typically, bartending is viewed as low-skilled work. This is reflected in Tapper's quick-fire mechanics where you deliver the same drink to an assortment of patrons as quickly as possible. That does not mean that the game itself has a low skill requirement. In fact, playing the emulated version proved difficult, and it was hard to get through a single level without making a mistake, immediately resulting in a "game over". In terms of representing the job of bartending, the bartender in Tapper has no conversation with the customer, making it a purely transactional relationship. There is no nuance to this form of service labour compared to interactions in $V: C A B$. Unlike in Tapper, the player in $V: C A B$ has a level of autonomy, as Jill can select drinks based on the customer's desires and tastes. This can be viewed as high-skilled craft labour, feeding into the elements of a profession, rather than the low-skilled occupation bar work inhabits (Fowler, 2017). Extensive knowledge of the ingredients and widely varying drink recipes are key for the player to succeed in satisfying the customer and completing a full day's work with no mistakes.

In addition to the level of skill simulated in these bartending games, the financial precarity associated with working-class labour under capitalistic structures is also present in both the games' narratives and mechanics. In Tapper, chasing down tips at varying points of the bar rarely pays off, as the player more often than not misses drink orders and catching glasses - even the current world champion leaves tips behind in pursuit of a higher score (Free Play Arcade, 2019). In $V: C A B$, getting an ambiguous drink order wrong (customers often ask for something "unique" with little indication of what that entails on the vast menu) results in a significant drop in the player's endof-day bonus and tips. The management behind these bars exist solely as branding 
or a one-time visit from "corporate", leaving these bartenders at the mercy of their customers and co-workers.

Figure 3 Early roots of virtual bartending

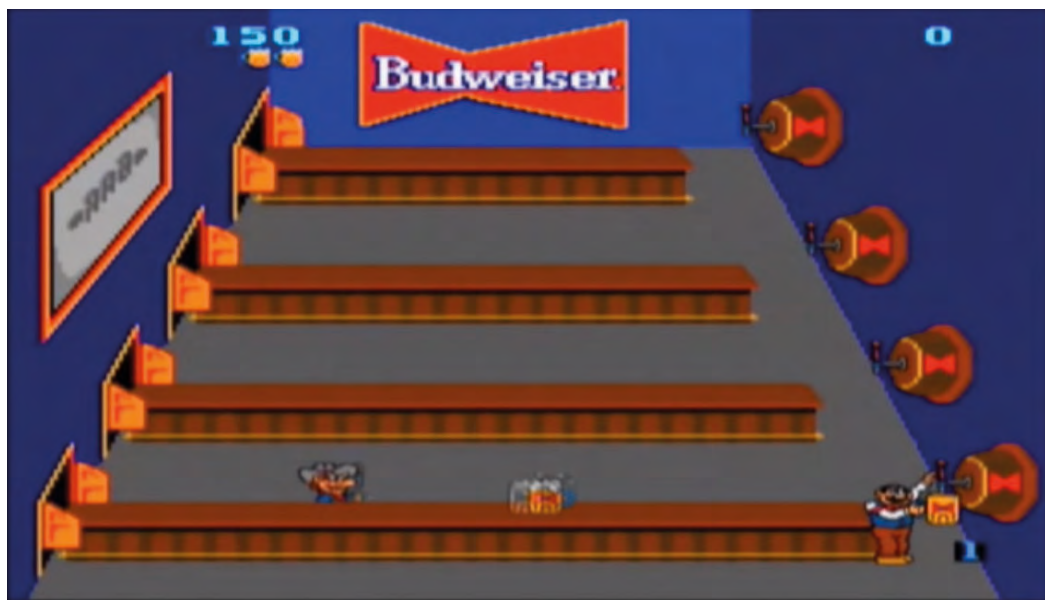

Comments: Tapper has, over the years, been franchised by Root Beer, Budweiser, and Mountain Dew. Above, a Budweiser banner can be seen topping the screen.

Source: Tapper (Marvin Glass and Associates, 1983)

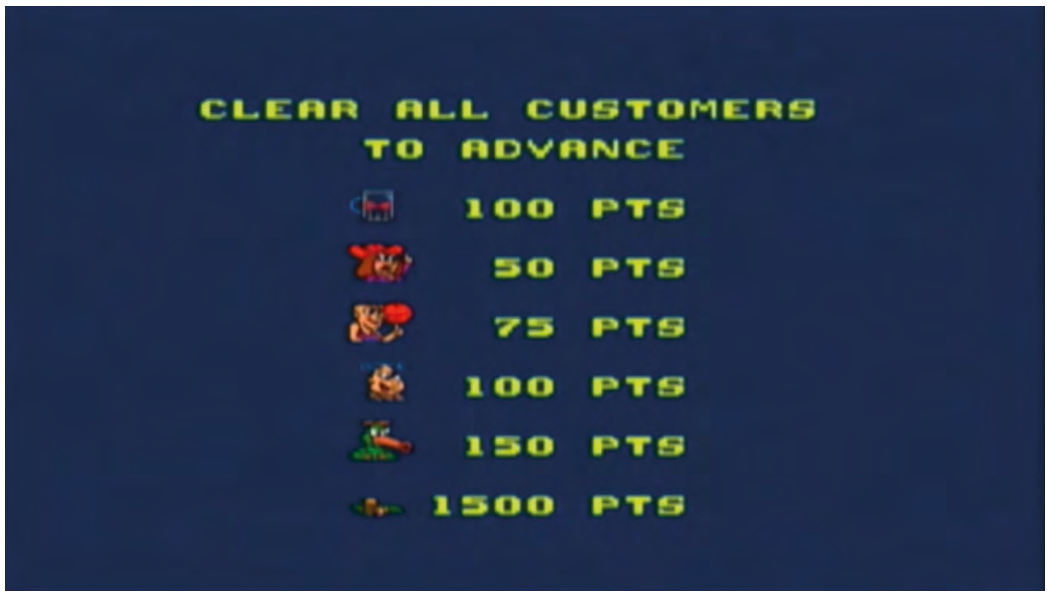

Comments: Level score system shown to the player at the start of the game.

Source: Tapper (Marvin Glass and Associates, 1983)

\section{VA11 HALL-A: A Cyberpunk Action Bartender}

VA11 HALL-A: Cyberpunk Action Bartender $(V: C A B)$, a cocktail-mixing visual novel set in the gritty cyberpunk dystopia "Glitch City", features the protagonist Jill, a twenty-something jaded bartender. The player mixes different drinks for clientele, while chatting with them, hearing their life stories, and learning their "usual". The player has a selection of six ingredients to mix, using a recipe system in order to create them correctly, and must remember particular clients' usuals in order to score higher tips at the end of each day. Perfecting drink serving also allows players to gain rare interactions and endings with different NPCs (non-player characters). 
Aside from physical demand, a significant aspect of bartending involves the expectation of emotional labour between the customers and the bartender. Grazian (2009: 909) describes bars as "third places", where patrons feel the bar environment is "inclusive" and a "social leveller". This, mixed with the inhibition-reducing effects of alcohol, allows customers to feel comfortable being vulnerable in these spaces, discussing emotional issues and using the bartender as a sounding board for advice. This form of emotional labour is present in $V: C A B$ as Jill regularly listens to the ramblings of her clients, offering counsel through the conversations, and rarely conceding information about her own personal struggles until it is forced out of her by a customer-turned-friend. In this way, the bartender can act as the "poor man's therapist", not necessarily a heroic characteristic, but perhaps in the wake of mental health crises, it can be read as such.

\section{Figure 4 Virtual bartending in the future}

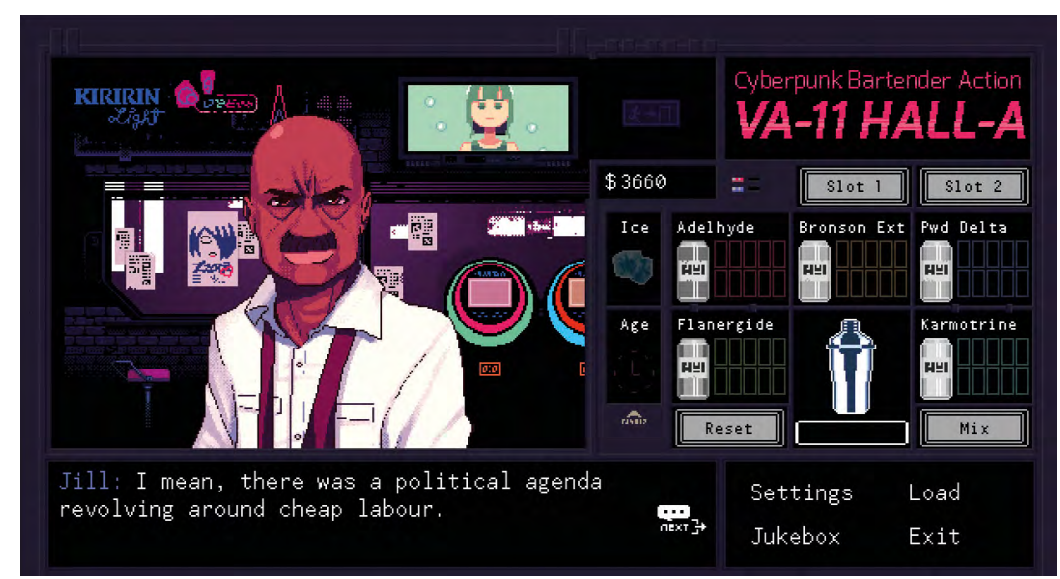

Comments: The screenshot shows a typical interaction screen between Jill and a customer.

Source: VA-11 HALL-A (Sukeban Games, 2016)

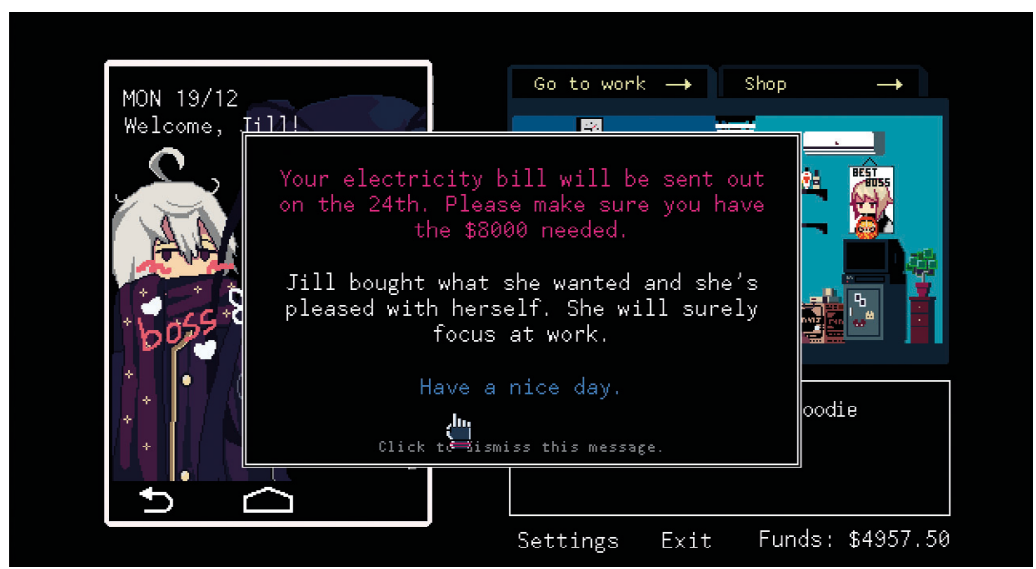

Comments: Sudden bills appear when Jill returns home for the day.

Source: VA-11 HALL-A (Sukeban Games, 2016) 
In sum, due to the precarious nature of their working-class service-industry jobs, the protagonists in these two games do not have the capacity to be a working-class hero in the typical sense. They do, as shown in $V: C A B$, participate in feminised emotional labour to sometimes support their customers, but this is not reminiscent of the masculine, working-class hero later discussed in games like The Firemen (1994). In this light, they are unable to take care of themselves in the face of financial precarity, and the job takes precedence over their own needs most of the time. The tracking of income (either as points or a tab at the end of the day) sits at the heart of both games' mechanics, reinforcing the financial precarity felt in typical working-class jobs and trying to make ends meet. Unlike other hero-driven videogames - where the game supports and facilitates the success of the hero - these two games exist as the inverse, with failure being the result of contextual precarity communicated through the games' stories and mechanics.

\section{Cleaning up the galaxy: Class mobility and janitorial labour}

Our investigation of janitorial work in videogames juxtaposes a decades-old adventure game series, Space Quest, with Diaries of a Spaceport Janitor, a life- and job-simulator released during an influx of empathy-oriented and critically designed titles following the game industry's post-2008 “indie boom”. Space Quest's protagonist, a janitor named Roger Wilco, is characterised over the course of the series' first three instalments by using social and cultural markers of class to generate humour, relying on and reinforcing media stereotypes of the typical working-class man as a "buffoon or bungler" (Butsch, 2017). Consequently, his arc more closely resembles that of the "chosen zero" archetype than that of an action hero. Conversely, the spaceport janitor's plight in Diaries simulates the challenges of working-poor class status by having players navigate the performance of virtual blue-collar labour in conditions that are, within the game world, exploitative and unsafe. Diaries intentionally sheds the typical progress narratives of videogame heroes, wherein one levels-up or gains power over time by using a combination of game elements to express how class - specifically power relations related to one's class position - impacts prospects of upward mobility and overall quality of life.

\section{Space Quest}

Space Quest is a series of comic science-fiction DOS games made by Two Guys from Andromeda and published by Sierra On-Line between 1986 and 1995. To progress, players manually type commands into a text parser to direct Roger, a lazy janitor stationed on a spaceship, to demonstrate the necessary skill and expertise for "cleaning up the galaxy" and saving the day. When the vessel is boarded by hostile aliens, Roger is only spared and involuntarily thrust into a hero's adventure because he took a conveniently timed nap inside a broom closet (The Sarien Encounter). Because Space Quest's situational comedy and humorous storytelling frequently hinges on Roger's "stereotypic ineptitude, immaturity, stupidity, [or] lack of good sense" (Butsch, 2003: 21), he is immediately codified in such a way that he conforms to enduring negative media tropes surrounding working-class men.

Cut-scenes make up much of Space Quest's exposition, precluding players' influence over major story beats. Resultingly, the player's relationship with Roger is less direct 
than when role-playing as $N e o C a b$ 's Lina or $V: C A B$ 's Jill. Instead, the player's role is to do damage control, setting Roger on the correct path and managing his choices to best compensate for his incompetence and lack of motivation. Using trial and error, players input commands for Roger to "look around" environments or "pick up" and "use" objects. While correct choices prompt the narrators to praise Roger's achievements and genius, incorrect choices often trigger humorous lose states which subject him to mockery and derision. Arguably, this way of structuring play reinforces caricatures of the blue-collar working man as one who stumbles into the inciting action and relies on others to solve problems (Butsch, 2017; Kendall, 2011). Combined with interactions with NPCs and set pieces where Roger's classed attributes (such as frugality, limited disposable income, and employment as a "low-skilled" worker) are joked about, Space Quest masks and softens the tensions and moral discomfort of class struggle using comic relief (Deery, 2017).

Figure 5 Janitorial life as comic relief

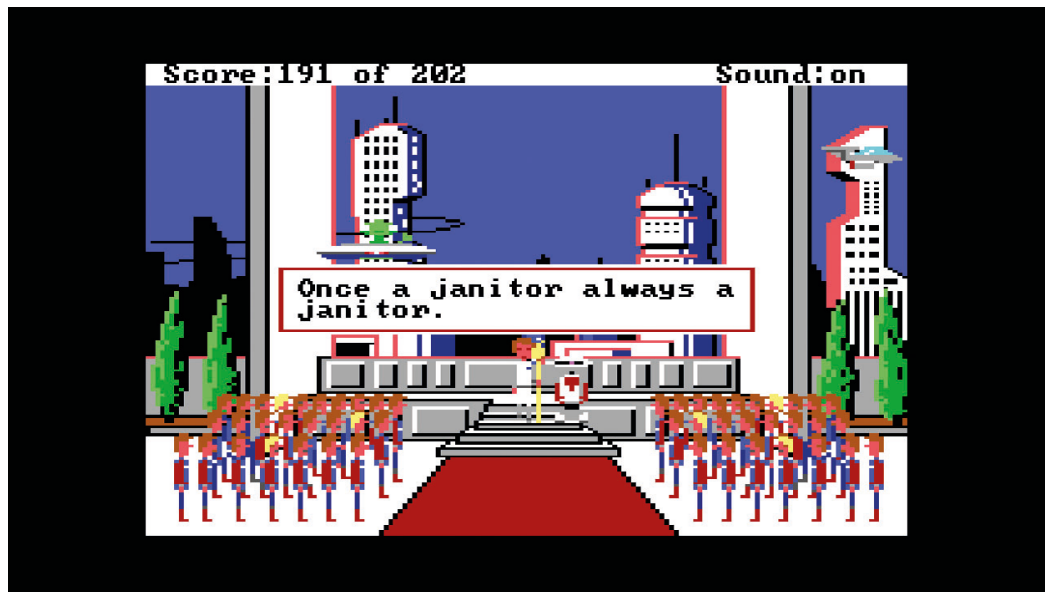

Comments: Roger is awarded with a golden mop for preventing the destruction of the planet Xenon. The narrators declare "once a janitor, always a janitor".

Source: Space Quest l: The Sarien Encounter (Two Guys from Andromeda, 1986)

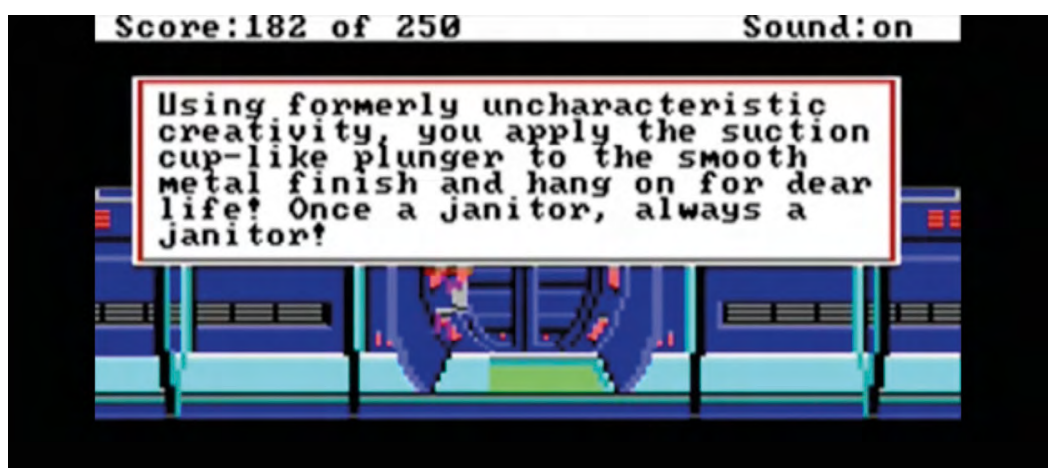

Comments: Roger avoids falling to his death by comically clinging to a plunger.

Source: Space Quest II: Vohaul's Revenge (Two Guys from Andromeda, 1987) 


\section{Diaries of a Spaceport Janitor}

Diaries of a Spaceport Janitor was developed by Sundae Month and published by tinyBuild games in 2016. Players assume the role of a "girlbeast" who works as a trash incinerator tasked with cleaning an alien marketplace and saving enough of their meagre income to afford a means of escape (tinyBuild Games, 2016). Echoing the retail-simulation game Cart Life (Hofmeier, 2010), Diaries models the Sisyphean difficulty of earning a living as a member of the working poor while staying fed, affording regular access to (sometimes gender-affirming) medical care, and attaining life goals that are unrelated to work. Diaries brings the performance of janitorial work to the fore. Between moments of downtime in a monotonous and inescapable day-night cycle, players must burn as much trash as possible to maximise the next day's pay. Much like in Tapper (Marvin Glass and Associates, 1983), this involves the execution of repetitive, seemingly "lowskilled" tasks - in this case, picking up objects off the ground and deciding to keep, burn, or attempt to sell at the risk of a reduction in pay.

The precarity of the spaceport janitor's work is emphasised by embedding players' labour in tangible institutions and systems: one's ability to save funds is at the mercy of fluctuating market prices, inconsistent pay rates, corrupt law enforcement, restrictions on the tools and hours available for doing work, the unreliability of vendors' stocks and prices, gender dysphoria, and even favour with the deities. Evidently, janitorial work in Diaries models the consequences of low wages and part-time employment brought on by the feminisation of the service industry under neoliberalism (Sherman, 2009). In part, this is because the janitor's job is municipally subsidised, and so the game acknowledges what consequences workers face when governments operate as a business, for example by taking steps to keep overhead costs - including employees' salaries - as low as possible rather than providing a living wage.

Second, this is because of how Diaries handles emotional labour, which is only expected from the spaceport janitor insofar as they are dealing with gendered street harassment or snide put-downs from vendors selling prohibitively expensive goods. However, unlike the protagonists in Neo $C a b$ and $V: C A B$ - who regularly interface with customers whose evaluation directly impacts how much they are paid - the spaceport janitor is alienated from the adventurers and merchants who frequent the marketplace, tending to be ignored completely unless the interaction involves a quest, sale, or trade. The janitor is also alienated from other sanitation workers (there are none) and from the value of their own labour (as evidenced by the random pay rate). It follows that Diaries reflects actual struggles currently associated with increasingly invisible and isolated low-wage cleaning work (Soni-Sinha \& Yates, 2013). 
Figure 6 Precarity and janitorial work

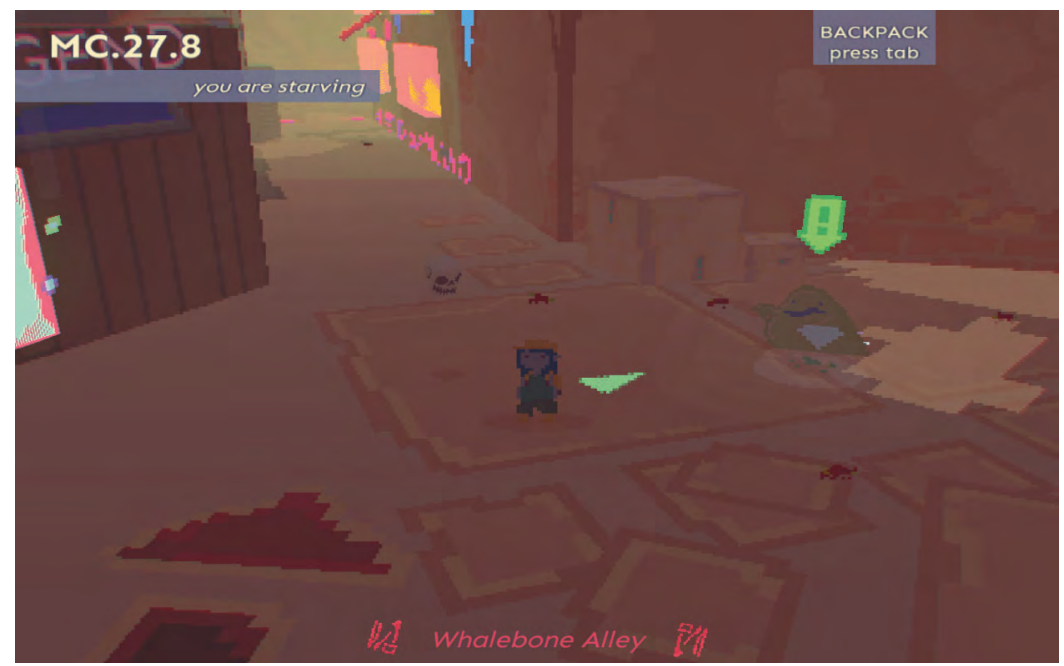

Comments: The screenshot shows the janitor attempting to complete a quest while savings run low while the indicator in the left corner warns "you are starving".

Source: Diaries of a Spaceport Janitor (Sundae Month, 2016)

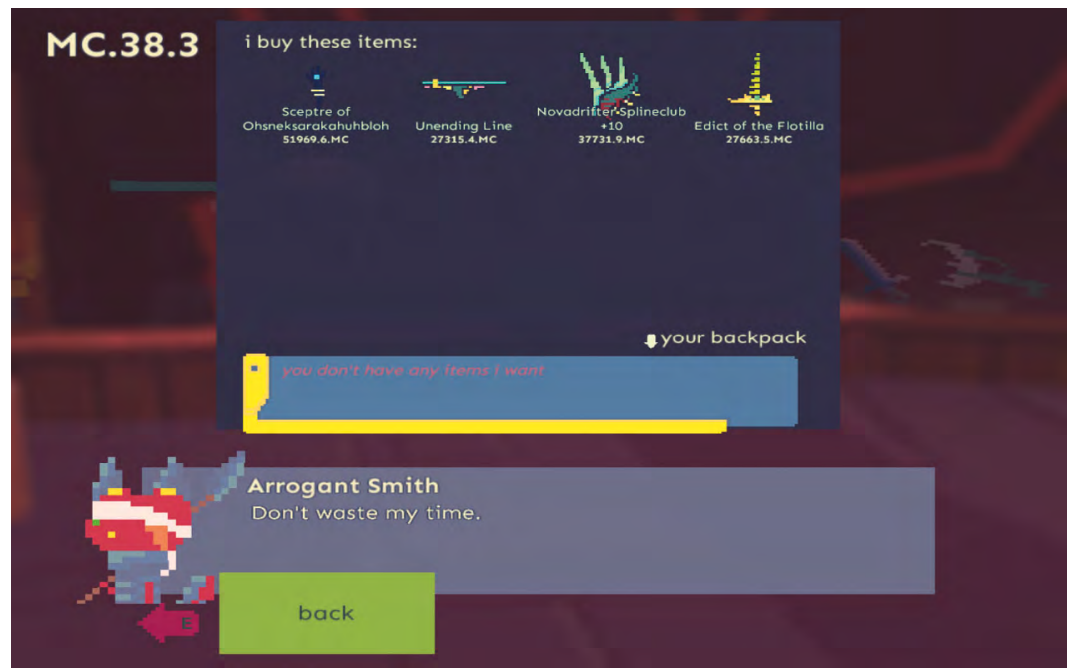

Comments: An arrogant Smith dismisses the janitor for not being able to afford their wares and wasting their time.

Source: Diaries of a Spaceport Janitor (Sundae Month, 2016)

Analysing these games as a pair shows that each protagonist embodies particular orientations to neoliberal ideals such as free-market competition, personal responsibility, and meritocracy, or the idea that the successes and value of an individual are fair, equitable, and direct products of their own hard work. Roger's inability to "officially" cease being a janitor is routinely used as a punchline - one centred around subverting audience expectations by relegating a heroic, cisgender, able-bodied white man to "low-skilled" and unglamorous work that (perhaps not coincidentally) is historically associated with women and the domestic sphere. However, Roger's mistakes are presented as tempo- 
rary comedic setbacks, while his successes are integrated into the story, which frames his progress as a product of his own efforts and merits despite players actively pushing for him to fail upward into hero status. So, while stereotypes of working-class men as buffoons or bunglers are rooted in emasculation (Butsch, 2017), Roger's masculinity is reasserted by naturalising his aptitude for adventuring and his propensity for heroics. The result is a character arc that is deeply informed by privilege, in particular, ease of upward mobility.

It is difficult to compare a comedy game with one that provides an intentionally uncomfortable critique of capitalism at work. Yet, this analysis has generated some insight into the variety of ways cleaning work has been contemplated and codified into games. Truly, Roger's job-title as “janitor” becomes increasingly symbolic as the series progresses and, by the end of the third instalment - The Pirates of Pestulon (1989) - his status as an action hero is firmly cemented. Rejecting the humble connotations associated with janitors keeping the universe clean, Roger assumes a sort of patriarchal responsibility as its brave, space-wandering custodian - a job he is repeatedly appreciated and rewarded for succeeding at despite his minimal efforts. By way of his privilege, Roger is easily swept up into a life of heroics that the spaceport janitor aspires to have but is systemically (and systematically) excluded from.

Diaries contrasts this by simulating an anti-adventure wherein the protagonist is actively punished for pursuing adventure and denied any opportunity to accomplish feats of heroism. By integrating the performance of labour into the structures and institutions of an unforgiving world, it expresses how progress and stability are affected by a host of external forces and oppressive conditions that are beyond any individual's control. Like Lina and Jill, the spaceport janitor does need to employ specific skills in order to survive (for example, time management). However, these centre more around managing the impact of exploitative and unsafe working conditions on the janitor's well-being than the management of relationships with clients and customers. Finally, by incorporating the preservation of one's welfare under capitalism into the act of doing labour in a fantastical science-fiction videogame setting, Diaries produces a sort of metatextual critique of traditional progress narratives in games. The spaceport janitor's journey tells us that hard work is not always enough to earn an upgrade or move on to the next level.

\section{"Just doing my job": The firefighter as blue-collar hero}

Unlike taxi drivers, bartenders, and janitors, firefighters have long cemented their status as working-class heroes. This heroic tradition extends back well into the nineteenth century, where the occupation has been celebrated through song, news reels, and other popular media forms (Cooper, 1995). When seeking out reasons for this rise to heroic status, Cooper lays out several thematics, two of which prove pertinent to their videogame depictions. First, the firefighter has been mythologised through their adversary, the out-of-control blaze that is commonly "metaphorized as an enemy, a dragon, a fiend out of hell" (Cooper, 1995: 142). Unlike other occupations ascribed heroism - such as police officers and soldiers - the firefighter's enemy is unambiguously destructive, allowing them to embody chivalric ideals while shirking moral baggage. Second, despite these heroics, the firefighter has been consistently framed as "simply an ordinary man 'doing 
his duty,' a phrase repeated over and over again by firemen themselves and by those who wrote about them" (Cooper, 1995: 162). This characterisation is rooted in tropes of working-class masculinity, echoed by Joan C. Williams (2017: 20), in which rigid self-discipline and "reining yourself in so you don't have an attitude" are required to complete challenging or menial work while accepting no reward beyond the satisfaction of a job well done and a paycheck to bring home to your family.

Although the firefighter's relationship to the flames they extinguish may be uncomplicated, more nuanced tensions have arisen in their line of work - both ethnographic studies and fictitious accounts of firefighting describe class conflict in which the blue-collar values of the firefighter are put at odds with white-collar ideals. Whereas firefighters are stereotypically imagined as physically fit, able-bodied, practical, and steeped in technical know-how, white-collar workers are characterised by those in the fire service as "soft" and "out of touch" with the on-the-ground needs of people (Thurnell-Read \& Parker, 2008: 132). Historically, this tension manifests as derision toward the administrative wings of the fire service and a resistance toward progressive mandates - perhaps most notoriously affirmative action (Carroll, 2011) - and translates into media depictions of white-collar workers as antagonistic or hapless. This is in contrast to other working-class professions, who often find themselves at the whim of their bosses and clientele, as firefighters are often depicted as possessing power and agency that transcends both class and rank. As can be seen in The Firemen and Real Heroes: Firefighter, the firefighter's victory over the dual antagonisms of fire and class defines videogame simulations of the fire service.

\section{The Firemen}

The Firemen is a single-player action-adventure game published in 1994 by Human Entertainment for the Super Famicom. Pete Grey is the protagonist, the lead member of a futuristic fire-service team tasked with quelling a raging fire inside the Metrotech industrial office complex. Controlling Pete alongside his novice partner Danny, players navigate the engulfed Metrotech building, putting out fires and rescuing civilians. Despite the firefighting theme, the title bears much in common with the "shoot 'em up" videogame genre. Players can spray their firehose in eight directions and switch between two firing modes - a powerful jet stream and a wide burst of water - echoing weapon types featured in games such as Contra. The titular firemen also have access to "extinguishing bombs" (essentially grenades) that disperse flames over a large area and must strafe and military-crawl to progress past certain obstacles. Recalling Cooper's (1995) metaphorisation of fire as a tangible foe, The Firemen simulates firefighting as a battle against numerous anthropomorphised blazes, invoking military themes while carrying none of the moral baggage that often accompanies them. 
Figure 7 Firefighters as heroes

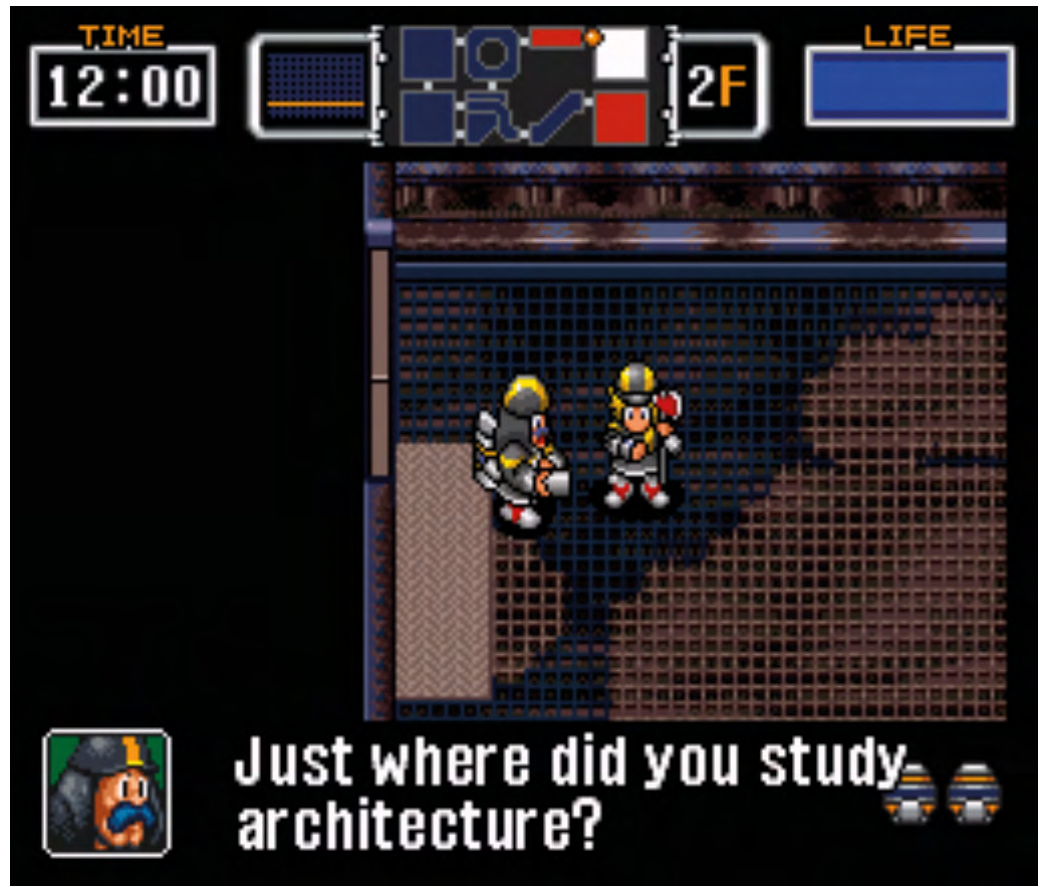

Comments: The screenshot shows Pete Grey verbally berating Frank Weller, the building's architect, over the radio.

Source: The Firemen (Human Entertainment, 1994)

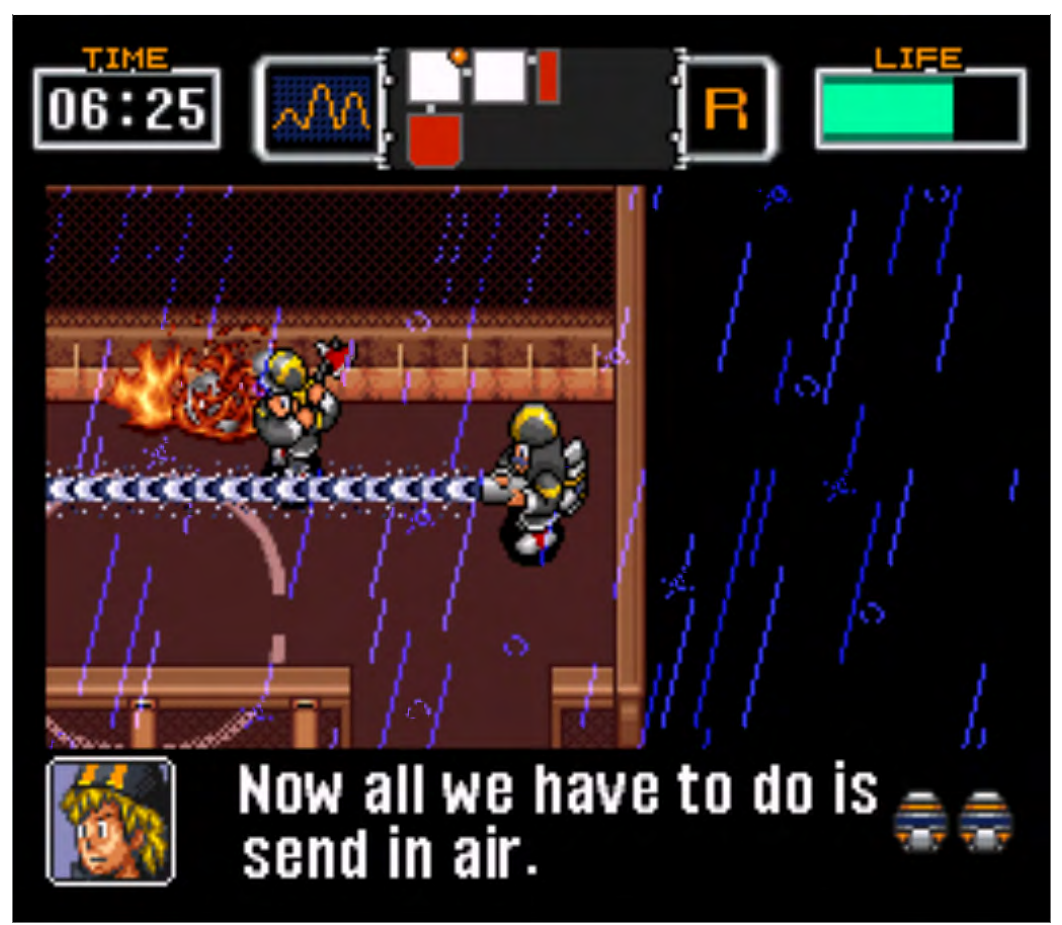

Comments: The screenshot shows the protagonists combatting flames atop the Metrotech complex.

Source: The Firemen (Human Entertainment, 1994) 
Class tensions arise in The Firemen in two key ways. First, the Metrotech complex which strongly resembles a white-collar office building - is imposed as a key antagonist throughout the game. Portions of the building collapse and contract, transforming office desks and computers into a dangerous labyrinth for the firefighters to navigate. Second, Metrotech architect Frank Weller is introduced mid-way through the gameplay and, despite being presented as an ally, becomes an immediate target of the firefighters' derision. Accusing Frank of being out of touch, Pete interrogates the architect's credentials and his design of the building, angering and flustering the white-collar worker. This tension is not fully resolved until the end scene of the game where Frank begrudgingly defers to Pete's expertise, acknowledging that he "learnt a lot" through his guidance and asks Pete to "remind me not to make the same mistakes again". Humbled by Pete's heroism, Frank assumes a subordinate role to the firefighter's courage and know-how.

\section{Real Heroes: Firefighter}

These class tensions also arise in Real Heroes: Firefighter, a first-person shooter-style game developed by Epicenter Studios and published for the Wii in 2009. Unlike The Firemen, where players control a veteran of the fire service, Real Heroes: Firefighter's protagonist is a probationary firefighter completing his first missions. The opening scene introduces the "probie" to a wide array of firefighting tools: the firehose, an extinguisher, a crowbar-like Halligan tool, a fire axe, hydraulic spreaders, and a rotary saw. Other firefighters directly state that proficiency with these tools is crucial to performing the job properly, reinforcing commonly cited blue-collar values of occupational competence and technical mastery (Thurnell-Read \& Parker, 2008). Where both The Firemen and Real Heroes: Firefighter rely primarily on shooter mechanics, Real Heroes also simulates real-life firefighting tools as skill challenges by leveraging the Wii's motion controls. Whether prying open a jammed door with a crowbar or tearing off a car door with the "jaws of life", the player must continuously demonstrate their technical expertise.

Figure 8 Virtual firefighting

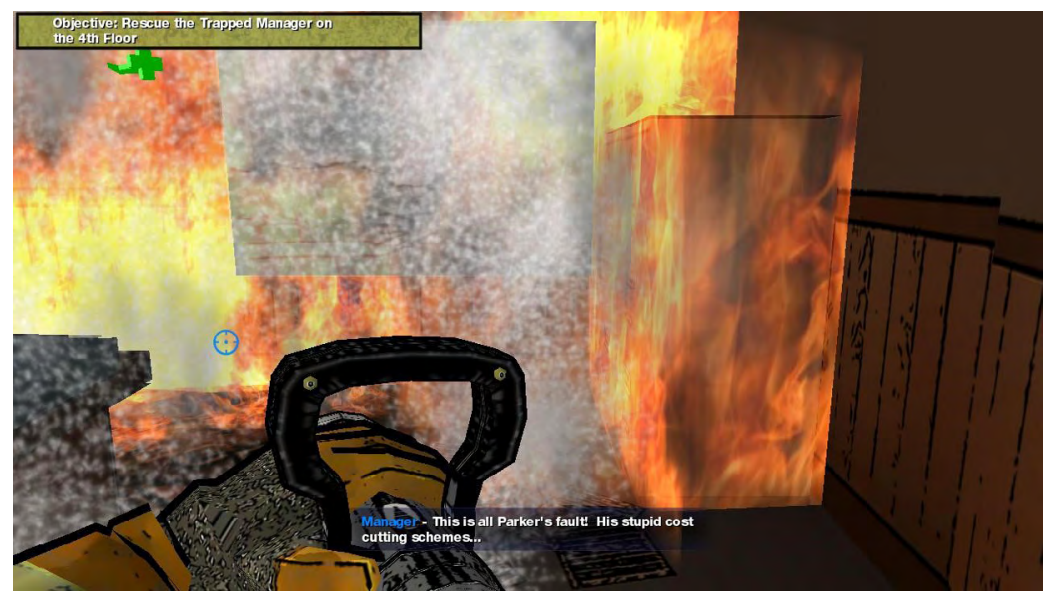

Comments: The screenshot shows white-collar workers bemoan their dangerous, cost-cutting measures (while trapped behind a wall of fire). Source: Real Heroes: Firefighter (Epicenter Studios, 2009) 


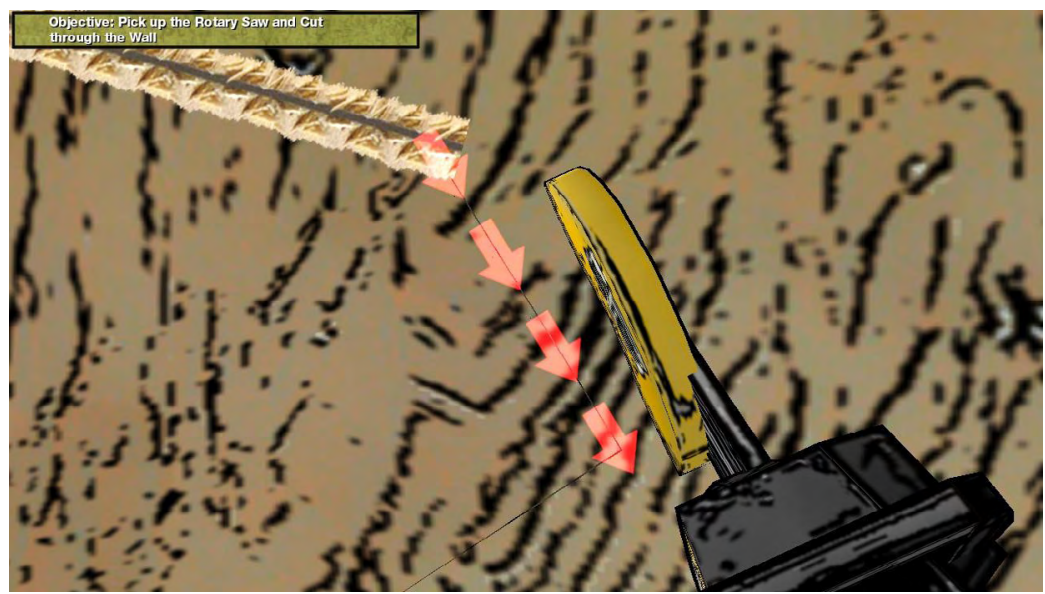

Comments: The screenshot shows a sequence where the player must operate a rotary saw with the Wii's motion controls in order to progress. Source: Real Heroes: Firefighter (Epicenter Studios, 2009)

Despite a transition into 3D, the objectives of both of these firefighting titles are roughly the same: players must progress through several flaming locales, putting out fires and rescuing civilians. The first level of the game parallels many aspects of The Firemen's Metrotech tower, but the white-collar workers take on a different role. Instead of berating a building architect over the radio, as with Frank Weller, Real Heroes: Firefighter fosters further ridicule by requiring you to rescue a pair of building managers during the opening mission. Panicky and helpless, the managers spout their regrets over "cost-cutting measures", with the firefighters even referring to them as "jerks" before guiding them to safety. As their workplace crumbles around them, these characters juxtapose the handson expertise of the firefighter with the perceived softness and haplessness of white-collar workers. Unlike the protagonists in Neo Cab, V:CAB, and Diaries of a Spaceport Janitor - who find themselves somewhat at the whim of the capitalist structures around them - these depictions of firefighters are fully empowered. Their heroic stature and expertise seem to eclipse class, positioning them as self-sufficient and powerful, even though they ostensibly exist in the same neoliberal environment as other working-class professions. In both The Firemen and Real Heroes: Firefighter, the firefighter emerges triumphant over both out-of-control flames and the follies of out-of-touch managers and professionals.

\section{Conclusion}

As these paired examples have shown, socioeconomic class can and does play a key role in a variety of videogames across a span of decades. We have not explored here how advancing technological capabilities have shaped the games detailed above, but a few things are evident. First, increased graphical fidelity is not a requirement for a game to make a meaningful statement or advance an argument. Second, the increasing popularity and number of story-based games has dovetailed with rising concerns over neoliberal politics to give game developers new interests and new ways to build worlds and tell stories about workers, the everyday, and challenges that are about more than high scores and slaying monsters. 
Yet, despite our emphasis on everyday professions, the objects of our research do not completely shirk the fantastical, nor do they shy away from over-the-top heroics. In the Space Quest series, intergalactic janitor Roger Wilco somehow retains his working-class demeanour despite being thrust into extraordinary situations, such as slaying alien beasts or even saving the universe. The Firemen glorifies a working-class occupation in a fashion that echoes Hollywood blockbusters such as Die Hard and Armageddon, positioning its protagonists in direct conflict with semi-futuristic, white-collar settings. Both Neo Cab and VA11 HALL-A: Cyberpunk Action Bartender take place in dystopian futures, with players attempting to complete their job despite strange new workplace realities (and even their own pending obsolescence). That displacement provides a familiar setting for players, but can also weaken the force of the statement being made, as the situation is one step removed from "our" current reality.

Certainly, there is more to say about each of these games, as well as additional games that feature the jobs we have identified here. Our intent was not to provide exhaustive analysis of each game or game pairing, but rather to point to the potential richness that even "older" or seemingly "simpler" games offer us in embodying class in varying ways. Games not only provide representations and narratives, but also mechanics and rules that individuals must navigate, accept, or reject as they play. Many more games should be studied in this manner, either across time or in comparison to other media forms, to see how the politics of class are being embodied, as well as how they shift or remain the same.

Finally, although the fantastic trappings of some game scenarios may seem detrimental to analysis, we argue that the opposite is true. The representation of working-class protagonists in extraordinary circumstances renders visible their purported heroic attributes, reveals what aspects of their jobs are deemed important enough to be simulated across genres, and highlights which elements of an occupation have been deemed insufficient to satisfy a game's narrative arc. Even professions that already enjoy heroic status in our cultural imagination, such as firefighters, are often undermined by a desire to present larger-than-life challenges to players: The Firemen sends hordes of anthropomorphised blazes and malfunctioning robots at the player and, in a strange twist, the final mission of Real Heroes: Firefighter requires the player to slay a fire-spewing mechanical dragon at a theme park. It appears that, even with the most elevated of blue-collar positions, simply "doing your job" is not enough to provide a successful heroic narrative. In conclusion, we urge more games scholars to investigate the topic of class as it is present in videogames, not only including how it is present in characters' jobs, but how it influences storylines and narratives, how it might be present in game mechanics, and how game algorithms replicate, challenge, or reinforce a variety of class-related systems.

\section{Notes}

1. Research on socioeconomic class outside of game form, however, is more common. Previous work done on players from different socioeconomic classes has primarily focused on youth of differing socioeconomic status, finding that class influences make a difference in how and what individuals play (Andrews, 2008; Sims, 2014). Demonstrating how race is implicated in class contexts, DiSalvo and colleagues found that both access to computers (to play educational games), as well as game content itself, can be an issue, such that "the lack of characters of color and the general themes have little crossover or relevance for them or their community" (DiSalvo et al., 2008: 138). Other studies point to the importance of both the place in which that gameplay occurs as well as the platforms on which games are played, both of which are tied to socioeconomic class (Narine \& Grimes, 2009). 
2. A video of the previous world record holder showed the extent of levels and gameplay in Tapper beyond an emulator, and was used for this analysis (Free Play Arcade, 2019).

\section{References}

Aliyu, M. (2020, February 28). Opinion | Cabdrivers like me don't want charity. We want justice. The New York Times. https://www.nytimes.com/2020/02/28/opinion/cabdrivers-lawsuit-new-york.html

Andrews, G. (2008). Gameplay, gender, and socioeconomic status in two American high schools. E-Learning, 5(2), 199-213. https://doi.org/10.2304\%2Felea.2008.5.2.199

Butsch, R. (2003). A half century of class and gender in American TV domestic sitcoms. Cercles, 8, 16-34.

Butsch, R. (2017). Class and gender through seven decades of American television sitcoms. In J. Deery, \& A. L. Press (Eds.), Media and class: TV, film, and digital culture (pp. 38-52). New York: Routledge. https://doi.org/10.4324/9781315387987

Carroll, H. (2011). Affirmation reaction: New formations of White masculinity. Durham, North Carolina: Duke University Press.

Chance Agency. (2019). Neo Cab [MS Windows]. Fellow Traveller.

Chess, S. (2017). Ready player two: Women gamers and designed identity. Minneapolis, Minnesota: University of Minnesota Press. https://doi.org/10.5749/minnesota/9781517900694.001.0001

Consalvo, M., \& Dutton, N. (2006). Game analysis: Developing a methodological toolkit for the qualitative study of games. Game Studies, 6(1), 1-17.

Cooper, R. (1995). The fireman: Immaculate manhood. Journal of Popular Culture, 28(4), 139-170. https:// doi.org/10.1111/j.0022-3840.1995.1395768.x

Deery, J. (2017). TV screening: The entertainment value of poverty and wealth. In J. Deery, \& A. L. Press (Eds.), Media and class: TV, film, and digital culture (pp. 53-67). New York: Routledge. https://doi. org/10.4324/9781315387987

Deery, J. \& Press, A. L. (Eds.). (2017). Media and class: TV, film, and digital culture. New York: Routledge. https://doi.org/10.4324/9781315387987

DiSalvo, B. J., Crowley, K., \& Norwood, R. (2008). Learning in context: Digital games and young Black men. Games and Culture, 3(2), 131-141. https://doi.org/10.1177/1555412008314130

Epicenter Studios. (2009). Real heroes: Firefighter [Nintendo Wii]. Flying Tiger Entertainment.

Fleras, A., \& Dixon, S. M. (2011). Cutting, driving, digging, and harvesting: Re-masculinizing the working-class heroic. Canadian Journal of Communication, 36(4), 579-597. https://doi.org/10.22230/ cjc. $2011 \mathrm{v} 36 \mathrm{n} 4 \mathrm{a} 2419$

Fowler, J. (2017). The transformation of occupations: A case study of professionalism in cocktail bartending [Master's thesis, Eberly College of Arts and Sciences, Morgantown, West Virginia, USA]. https://doi. org/10.33915/etd.7087

Frasca, G. (2003). Simulation versus narrative: Introduction to Ludology. In M. J. P. Wolf, \& B. Perron (Eds.), The video game theory reader (pp. 221-236). New York: Routledge. https://doi. org/10.4324/9780203700457

Free Play Arcade. (2019). Tapper longplay by former world record holder! YouTube. https://www.youtube. com/watch? $\mathrm{v}=\mathrm{nt} 73 \mathrm{eVpQpW} 4$

Gailey, C. W. (1993). Mediated messages: Gender, class, and cosmos in home video games. Journal of Popular Culture, 27(1), 81-97. https://doi.org/10.1111/j.0022-3840.1993.845217931.x

Grazian, D. (2009). Urban nightlife, social capital, and the public life of cities. Sociological Forum, 24(4), 908-917. https://doi.org/10.1111/j.1573-7861.2009.01143.x

Helling, B. (2020, April 1). How much does an Uber driver make in 2020? [The Inside Scoop]. Ridester. Retrieved April 10, 2020, from https://www.ridester.com/how-much-do-uber-drivers-make/

Hitmaker Studio. (1999). Crazy taxi [Arcade game]. Sega.

Hofmeier, R. (2010). Cart life [MS Windows]. Adventure Game Studio.

Human Entertainment. (1994). The firemen [Super Famicom]. Nintendo.

Kendall, D. E. (2011). Framing class: Media representations of wealth and poverty in America (2nd ed). Lanham, Maryland: Rowman \& Littlefield Publishers

Kocurek, C. A. (2015). Coin-operated Americans: Rebooting boyhood at the video game arcade. Minneapolis, Minnesota: University of Minnesota Press.

Lupton, M. J. (1979). Ladies' entrance: Women and bars. Feminist Studies, 5(3), 571-588. https://doi. org $/ 10.2307 / 3177514$

Marvin Glass and Associates. (1983). Tapper [Arcade game]. Bally Midway.

Mitra, D. (2008). Punjabi American taxi drivers: The new white working class? Journal o Asian American Studies, 11(3), 303-336. https://doi.org/10.1353/jaas.0.0014 
Morton, L. (2018, June 11). How the creators of Neo Cab want to make emotion 'truly matter to gameplay'. PC Gamer. https://www.pcgamer.com/how-the-creators-of-neo-cab-want-to-makeemotion-truly-matter-to-gameplay/

Narine, N., \& Grimes, S. M. (2009). The turbulent rise of the 'child gamer': Public fears and corporate promises in cinematic and promotional depictions of children's digital play. Communication Culture and Critique, 2(3), 319-338. https://doi.org/10.1111/j.1753-9137.2009.01040.x

Neo Cab. (n.d.). Neo Cab [a game by Chance Agency]. Retrieved February 26, 2020, from https://neocabgame.com/press

Pérez-Latorre, Ó., Navarro-Remesal, V., Planells de la Maza, A. J., \& Sánchez-Serradilla, C. (2019).“Recessionary games: Video games and the social imaginary of the Great Recession (2009-2015). Convergence, 25(5-6), 884-900. https://doi.org/10.1177/1354856517744489

Pérez-Latorre, Ó., \& Oliva, M. (2019). "Video games, dystopia, and neoliberalism: The case of BioShock Infinite." Games and Culture, 14(7-8), 781-800. https://doi.org/10.1177/1555412017727226

Salaries HUB. (n.d.). Uber driver salary guide \& career outlook 2020. Retrieved February 26, 2020, from https://salarieshub.com/uber-driver-salary/

Sharma, S. (2014). In the meantime: Temporality and cultural politics. Durham, North Carolina: Duke University Press.

Shaw, A. (2014). Gaming at the edge: Sexuality and gender and the margins of gamer culture. Minneapolis, Minnesota: University of Minnesota Press.

Sherman, J. (2009). Those who work, those who don't: Poverty, morality, and family in rural America. Minneapolis, Minnesota: University of Minnesota Press.

Sims, C. (2014). 'Video game culture,' contentious masculinities, and reproducing radicalized social class divisions in middle school. SIGNS, 39(4), 848-857. https://doi.org/10.1086/675539

Soni-Sinha, U., \& Yates, C. A. B. (2013). 'Dirty work?' Gender, race, and the union in industrial cleaning. Gender, Work, and Organization, 20(6), 737-751. https://doi.org/10.1111/gwao.12006

Sukeban Games. (2016). VA11 HALL-A: Cyberpunk action bartender [PC, MS Windows]. Ysybyrd Games.

Sundae Month. (2016). Diaries of a spaceport janitor [MS Windows, macOS]. tinyBuild Games.

Thurnell-Read, T., \& Parker, A. (2008). Men, masculinities and firefighting: Occupational identity, shop-floor culture and organisational change. Emotion, Space and Society, 1(2), 127-134. https:// doi.org/10.1016/j.emospa.2009.03.001

tinyBuild Games. (2016, September 16). Diaries of a spaceport janitor. tinyBuild Games. https://www.tinybuild.com/diariesofaspaceportjanitor

Two Guys from Andromeda. (1986). Space quest I: The Sarien encounter [DOS computer game]. Sierra On-Line.

Two Guys from Andromeda. (1987). Space quest II: Vohaul's revenge [DOS computer game]. Sierra On-Line.

Two Guys from Andromeda. (1989). Space quest III: The pirates of Pestulon [DOS computer game]. Sierra On-Line.

U.S. News \& World Report. (n.d.). How much does a taxi driver make? Retrieved February 25, 2021, from https://money.usnews.com/careers/best-jobs/taxi-driver-andchauffeur

Williams, D., Martins, N., Consalvo, M., \& Ivory, J. D. (2009). The virtual census:Representations of gender, race and age in video games. New media and society, 11(5), 815-834. https://doi. org/10.1177/1461444809105354

Williams, J. C. (2017). White working class: Overcoming class cluelessness in America. Brighton, Massachusetts: Harvard Business Review Press.

(C) 2021 Nordicom and respective authors. This is an Open Access work licensed under the terms of the Creative Commons Attribution-NonCommercial-NoDerivatives 4.0 International Public licence (CC BY-NC-ND 4.0). To view a copy of the licence, visit https://creativecommons.org/ licenses/by-nc-nd/4.0/ 